\title{
Design of Control System for 4-Switch BLDC Motor Based on Sliding-Mode and Hysteresis Controllers
}

\author{
Mohammed Moanes Ezzaldean ${ }^{1}$, Qusay S. Kadhem ${ }^{2}$ \\ ${ }^{1}$ Department of Electrical Engineering-University of Technology, Baghdad-Iraq,30097@uotechnology.edu.iq \\ ${ }^{2}$ Department of Electrical Engineering-University of Technology,Baghdad-Iraq,naseem2017@yahoo.com
}

\begin{abstract}
This paper presents a design of a complete dual-loop controller for 4-switch brushless dc motor. In low power, low-cost applications, the 4-switch inverter topology is a felicitous alternative of the ordinary 6-switch inverter. The controller of the 4-switch $B L D C$ motor has to be uncomplicated and can be implemented without the use of expensive hardware to avoid increasing the overall cost of the drive system. Furthermore, the control must be able to deal with the known problems of the 4-switch drive which are speed limitation and high ripple torque. The proposed controller comprises sliding mode speed control and direct current hysteresis control. To investigate the performance of the proposed design, the system is modeled by using Matlab/Simulink, the results are obtained for different working conditions. The propitious results certify the applicability of the proposed controller in low-cost 4-switch BLDC motor drive systems.
\end{abstract}

Index Terms-Brushless dc motor, Hysteresis control, Sliding mode, 4-switch inverter.

\section{INTRODUCTION}

A brushless DC (BLDC) motor is an upgraded version of the conventional DC motor, in this motor, the commutator and the brushes have been replaced by electronic commutation system. BLDC motors are rapidly gaining popularity and are used in a wide range of applications such as industry, household, computers, automotive, etc. The construction of the BLDC motor is similar to the 3-phase permanent-magnet synchronous motor while the principle of operation is similar to the DC motor. The electrical power is supplied to the BLDC motor by using a 3-phase inverter which operates in accordance with the timing signals of the Hall-effect sensor. BLDC motor is characterized by many advantages, compared with other motors, such as high efficiency, high reliability, nearly maintenance free, high power density, high power factor, and low electromagnetic interface and noise levels[1,2]. Ordinary, the inverter of the 3-phase brushless de motor has six switches. For the fractionalhorsepower motor drive, cost minimization is the most important factor; therefore, efforts are being made to use less expensive types of the inverter. One of the good options is the 4-switch inverter, in recentyears, this inverter is extensively used to drive the BLDC motors in household appliances [1,2]. In 4-switch inverter topology, one pair of switches is replaced by two identical capacitors, thus two power switches with their control circuit are saved here. Thereby, the drive system has lower cost and less switching losses but the required control technique have to be more advanced taking into consideration that the control algorithm has not implemented by using expensive hardware like highspeed microprocessor or microcontroller which increase the overall manufacturing cost of the system. Within this trend, many control methods have been suggested as a torque controller and speed controller for the BLDC motor which is fed by the 4-switch inverter. B. Lee et. al. (2003) [3], proposed a low cost 4-switch BLDC motor drive, a novel direct-current controlled PWM scheme is designed and implemented to produce the desired static and dynamic speed-torque characteristics. A. Halvaei Niasar et. al. (2009) [4] proposed a macro-model to simulate of 4-switch, 3-phase inverter 
BLDC motor drive using switching functions, due to problems caused by eliminating two power switches, direct phase current (DPC) control technique is carried out, the model is demonstrated by simulations and experiments. S. B. Ozturk et. al. (2010) [5] presented a direct torque control (DTC) method for brushless dc motors using 4-switch inverter in the constant torque region. This technique introduces 2-phase conduction mode as opposed to the conventional 3-phase DTC drives, by properly selecting the inverter voltage space vectors from a simple look-up table at a predefined sampling time, the desired quasi-square current waveform is obtained. Shao et. al. (2015) [6] Introduced new dual loop control strategy for conventional 6-switch BLDC motor drive in which the current hysteresis control is adopted for the current loop, and the speed loop control is constructed based on sliding mode controller (SMC) and sliding mode observer (SMO), this control strategy shows obvious advantages in low overshoot level, fast speed response and adaptability to load variations.

This paper evaluates the application of the dual loop control strategy for the 4-switch BLDC motor drive system. The speed loop control is carried out based on the exponential approaching law sliding mode controller and the direct current hysteresis controller is adapted to perform the current loop.

\section{MATHEMATICAL MODEL OF THE BRUSHLESS DC MOTOR}

The following assumptions are considered in the mathematical model of brushless DC motor:

- The iron and mechanical losses are neglected.

- Winding resistances of all phases are equal.

- Mutual and self-inductances are constant.

- The magnetic saturation is neglected.

- The motor is star-connected.

The single-phase diagram of the three-phase BLDCmotor is shown in figure (1)[1]. The differential equation describing the electrical quantities per one phase of the motor is [1]:

$$
v=i R+(L-M) \frac{d i}{d t}+e
$$

Where:

$\mathrm{v}=$ the applied phase voltage in Volt

$\mathrm{i}=$ phase current in Ampere

$\mathrm{R}=$ per phase resistance of stator winding in Ohm

$\mathrm{L}=$ per phase inductance of stator winding in Henry

$\mathrm{M}=$ mutual inductance of winding in Henry

$\mathrm{e}=$ back emf which takes a trapezoidal form.

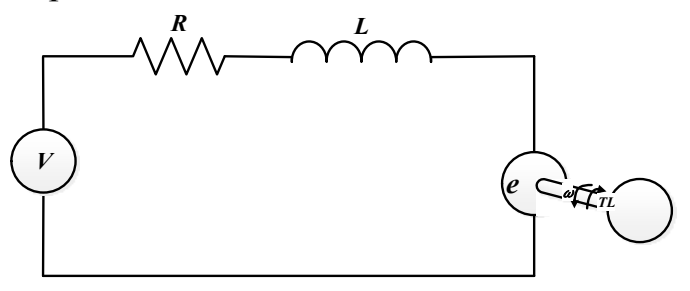

FIG. 1. EQUIVALENT CIRCUIT OF BLDC MOTOR.

To describe the mechanical behavior of the motor operation, the motion equation is included as[1]:

$$
T_{e}-T_{L}=J \frac{d \omega}{d t}+B \omega
$$


Where:

$T_{e}=$ electromagnetic torque $(\mathrm{N} . \mathrm{m})=k_{t} i$

$k_{t}=$ torque constant $(\mathrm{N} \cdot \mathrm{m} / \mathrm{A})$

$T_{L}=$ Load torque (N.m)

$J=$ rotor moment of inertia $\left(\mathrm{kg} \cdot \mathrm{m}^{2}\right)$

$B=$ viscous friction coefficient (N.m.s)

\section{ANALYSIS OF THREE-PHASE 4-SWITCH INVERTER}

The circuit diagram of the 4-switch inverter is shown in figure (2). During one cycle, the inverter has six modes of operation, the modes are listed in the table (1), figure (3) shows the circuit status for each mode of operation, only one switch is conducted in modes 2,3,5 and 6 whilst two switches in modes 1 and 4 . It could be noted that only phases $a$ and $b$ are controllable while phase $c$ is uncontrollable [3,5]. For BLDC motor, Low ripple torque and low noise operation can be achieved when their phase currents have quasi-square waveform [7,8]. Under the normal operating condition, the currents of the motor meet the following equation $[6,9]$ :

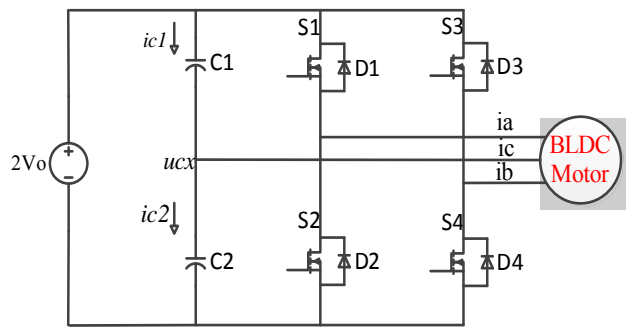

Fig. 2. THE CIRCUIT DIAGRAM OF 4-SWITCH INVERTER.

$$
i_{a}+i_{b}+i_{c}=0
$$

Equation (3) implies that control only two currents can guarantee outright current control of the motor system.

TABLE 1. THE MODES OF OPERATIONS FOR 4-SWITCH INVERTER

\begin{tabular}{cccr}
\hline Mode & Active Phase & Conducting Devices & Current Equation \\
\hline Mode 1 & $+\mathrm{c},-\mathrm{b}$ & $\mathrm{S}_{4}$ & $\mathrm{i}_{\mathrm{c}}+\mathrm{i}_{\mathrm{b}}=0, \mathrm{i}_{\mathrm{a}}=0$ \\
Mode 2 & $+\mathrm{a},-\mathrm{b}$ & $\mathrm{S}_{1}, \mathrm{~S}_{4}$ & $\mathrm{I}_{\mathrm{a}}+\mathrm{i}_{\mathrm{b}}=0, \mathrm{i}_{\mathrm{c}}=0$ \\
Mode 3 & $\mathrm{~S}_{1}$ & $\mathrm{I}_{\mathrm{a}}+\mathrm{i}_{\mathrm{c}}=0, \mathrm{i}_{\mathrm{b}}=0$ \\
Mode 4 & $+\mathrm{a},-\mathrm{c}$ & $\mathrm{S}_{3}$ & $\mathrm{i}_{\mathrm{c}}+\mathrm{i}_{\mathrm{b}}=0, \mathrm{i}_{\mathrm{a}}=0$ \\
Mode 5 & $+\mathrm{b},-\mathrm{c}$ & $\mathrm{S}_{2}, \mathrm{~S}_{3}$ & $\mathrm{I}_{\mathrm{a}}+\mathrm{i}_{\mathrm{b}}=0, \mathrm{i}_{\mathrm{c}}=0$ \\
Mode 6 & $-\mathrm{a},+\mathrm{b}$ & $\mathrm{S}_{2}$ & $\mathrm{I}_{\mathrm{a}}+\mathrm{i}_{\mathrm{c}}=0, \mathrm{i}_{\mathrm{b}}=0$ \\
\hline
\end{tabular}



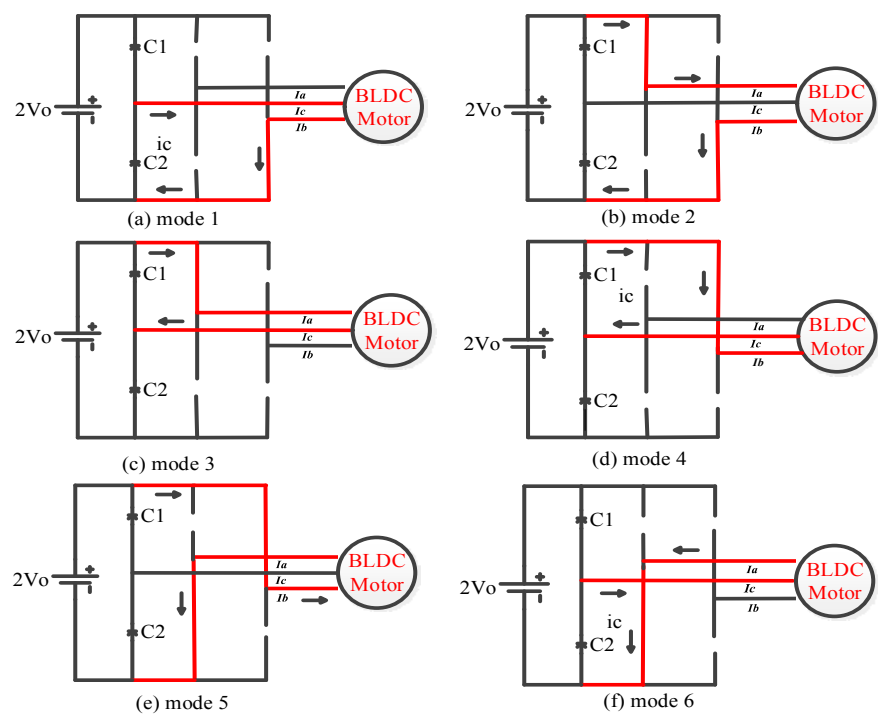

Fig.3. Operating STATUSES OF4-SWITCH INVERTER.

\section{DESIGN OF THE PROPOSED CONTROLLER}

The structure of the proposed controller consists of two-loops; the outer one is designed to perform the dynamic and static speed stability of the drive. The inner-loop is designed to maintain quasi-square waveform and regulate the maximum value of the current, a general block diagram of the controller is shown in figure (4).

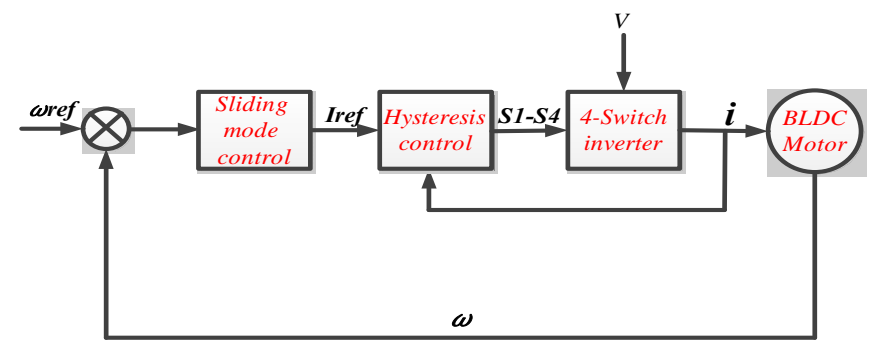

Fig. 4. STRUCTURE OF THE PROPOSED CONTROLLER.

\section{A. Sliding-Mode Speed Controller}

Sliding-mode controller is a non-linear control technique that treats the dynamics of non-linear systems by the implementation of a discontinuous control signal to force the system to slide along a predefined sliding surface. SMC is a variable structure control process, where the control system switches from one continuous structure to another depending on the status of the system. Design of sliding mode controller involves two tasks [6,10,11]:

1) Specify of a stable sliding surface on which the performance trajectory have ultimately to lie in.

2) Derive a suitable control low that enforces the performance trajectory to reach the sliding surface within a finite time.

The speed controller is designed to minimize the speed error, the output of this controller is considered as a reference current, which is designated as $u$. The motion equation of the motor can, then, be reformed as [6]:

$$
\mathrm{J} \dot{\omega}=\mathrm{k}_{\mathrm{t}} \mathrm{u}-\mathrm{B} \omega-\mathrm{T}_{\mathrm{L}}
$$

The sliding surface may be either linear or non-linear, for simplicity a linear surface is considered here. First, the speed error model is defined as: 


$$
e=\omega_{\text {ref }}-\omega
$$

Where $\omega_{\text {ref }}$ is the reference speed.

Moreover, the linear sliding surface (s) is written as:

$$
s(\omega)=e
$$

and

$$
\dot{\mathrm{s}}(\omega)=\dot{\mathrm{e}}=\dot{\omega}_{\mathrm{ref}^{-}} \dot{\omega}
$$

The control law, that allows the speed error to reach the sliding surface, has to be designed within the following condition [10]:

$$
s \dot{S} \leq 0
$$

Equation (8) is called the existence condition of the sliding mode controller. In respect to satisfying the searching condition, exponential reaching law approach is adopted. This law is given by [6]:

$$
\dot{\mathrm{s}}=-\psi \operatorname{sgn}(\mathrm{s})-\mathrm{ks}, \quad \psi>0, \quad \mathrm{k}>0
$$

Where $-k s$ is exponential term which guarantees that the sliding surface approached rapidly at large values of $\mathrm{s}$, and decreases gradually and eventually to zero when the system state approaching the sliding surface. Discontinuous term $-\psi \operatorname{sgn}(s)$ works on reaching the sliding surface within finite time but often causes chattering problem [10]. From equations(4), (7) and (9), the actual control law can be obtained as:

$$
u=\frac{1}{k_{t}}\left(J \dot{\omega}_{r e f}+B \omega+T_{L}+\psi J \operatorname{sgn}(s)+J k s\right)
$$

The existence condition can be written in details as:

$$
s(\omega) \dot{s}(\omega)=(-\psi \operatorname{sgn}(s)-k s) s \leq 0
$$

Practically, the load torque is unknown, wherefore it may be considered as a disturbance and be omitted from the control law. Based on that, the existence condition has to be modified as [6]:

$$
s(\omega) \dot{s}(\omega)=\left(-\psi \operatorname{sgn}(s)-k s-T_{L}\right) s \leq 0
$$

\section{B. Direct Current Hysteresis Controller}

The sliding mode controller provides the current controller by the required reference current signal where:

$$
I_{r e f}=u
$$

The decoder is a logic circuit that converts the signals of the hall-effect sensor to timing signals. The timing signals determine the intervals of the operating modes. Reference current generator circuit is designed to generate $\mathrm{I}_{\text {aref }}$ and $\mathrm{I}_{\text {bref }}$ according to $\mathrm{I}_{\text {ref }}$ value and the state of the decoder. Both of $\mathrm{I}_{\text {aref }}$ and $\mathrm{I}_{\text {bref }}$ have a magnitude of $\mathrm{I}_{\mathrm{ref}}, 0$ or $-\mathrm{I}_{\mathrm{ref}}$. The operation of the reference current generator circuit is illustrated in figure (5). 


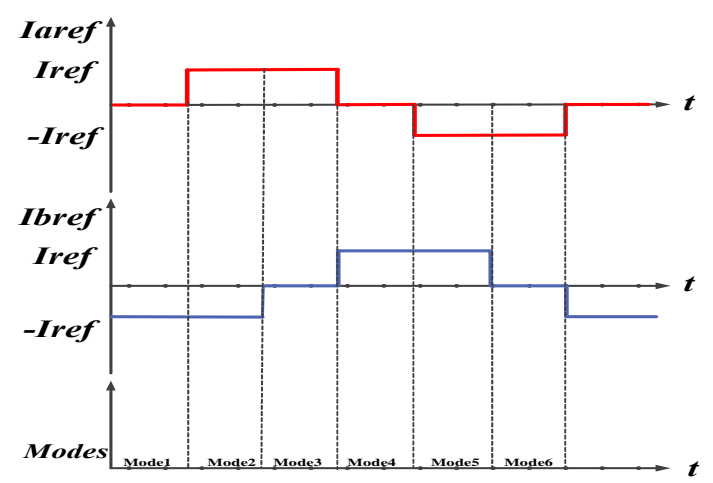

FIG. 5. SigNALS OF THE REFERENCE CURRENT GENERATOR.

The hysteresis current control works on enforcing the motor currents to take the quasi-square waveform. Let us consider the current $I_{a}$ here when $I_{\text {aref }}$ is positive or negative, $i_{a}$ will regulate within a small range around $\mathrm{I}_{\text {aref }}$ value. The regulation is performed by high-frequency switching of switches $\mathrm{S}_{1}$ and $S_{2}$. When $I_{\text {aref }}$ equals to zero, switches $S_{1}$ and $S_{2}$ will be turned off and $I_{a}$ will be zero [7]. The corresponding flowchart of controlling the current $\mathrm{I}_{\mathrm{a}}$ by hysteresis controller is shown in figure (6).

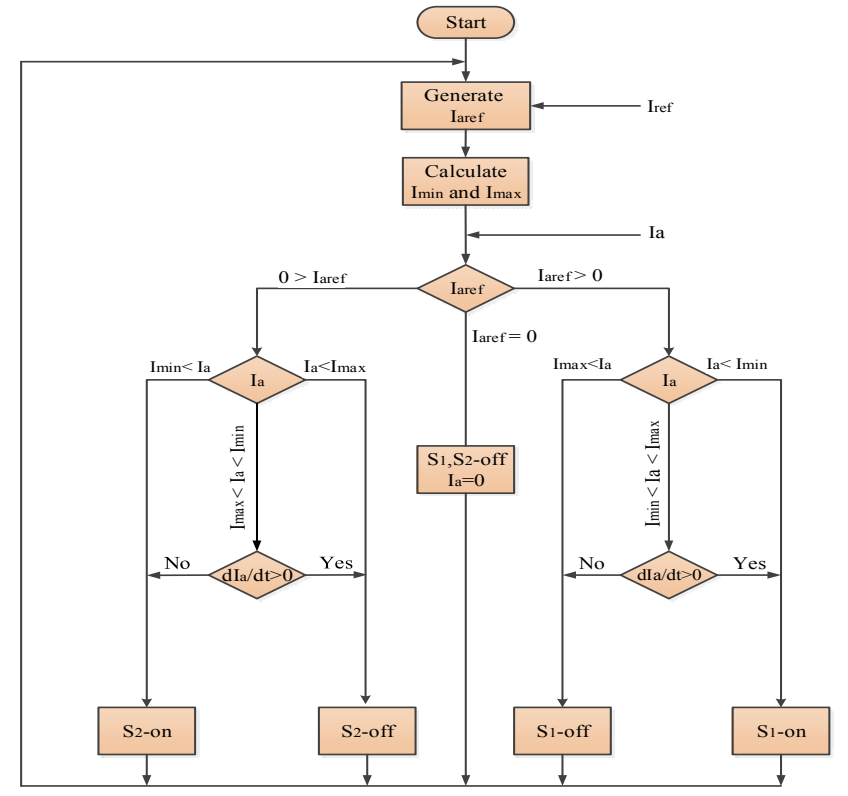

FIG. 6. FLOWCHART OF HYSTERESIS CONTROLLER.

In the case where the switches $S_{1}$ or $S_{2}$ off, the current $I_{a}$ completes its loop through the anti-parallel diodes $\mathrm{D}_{2}$ or $\mathrm{D}_{1}$, respectively [7]. Regulation of the current $\mathrm{I}_{\mathrm{a}}$ is shown in figure (7).

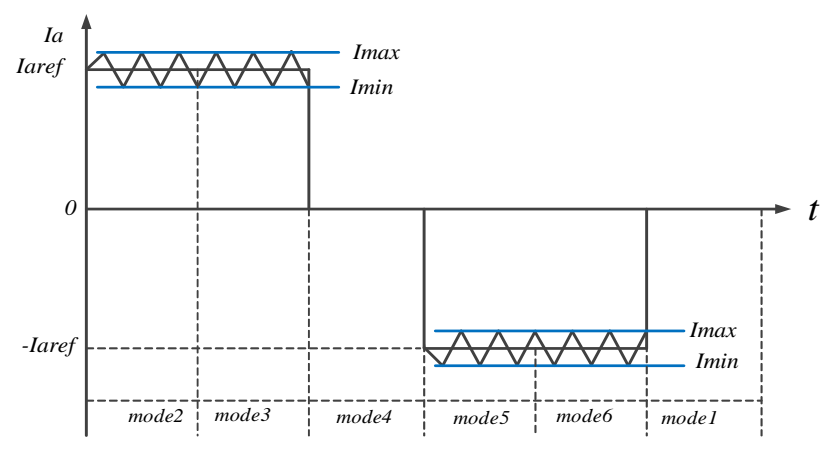

Fig. 7. RegUlAtion OF THE CURRENT IA 
A similar explanation can be given to describe the behavior of the current $\mathrm{I}_{\mathrm{b}}$. For $\mathrm{I}_{\mathrm{b}}$, the switches and diodes $\left(\mathrm{S}_{1}, \mathrm{~S}_{2}, \mathrm{D}_{1}, \mathrm{D}_{2}\right)$ are superseded by $\left(\mathrm{S}_{3}, \mathrm{~S}_{4}, \mathrm{D}_{3}, \mathrm{D}_{4}\right)$ respectively. In modes 2 and 5 , both of phases $\mathrm{a}$ and $\mathrm{b}$ are conducting current and phase $\mathrm{c}$ is regarded as a silent phase. However, the back emf of phase $\mathrm{C}$ may cause an unexpected and additional current which leads to distortion in $\mathrm{I}_{\mathrm{a}}$ and (or) $I_{b}$ [7]. Since the currents $I_{a}$ and $I_{b}$ are controlled independently, the phase $a$ and $b$ are regarded as the independent current source and the back emf of phase c can't act as a current source. In this way, the direct current hysteresis control is able to compensate the back emf and eliminate the current distortion problem.

\section{SIMULATION AND RESULTS}

In order to validate the proposed strategy, a simulation model has been developed by Matlab/Simulink, the block diagram of this model is shown in figure (8).

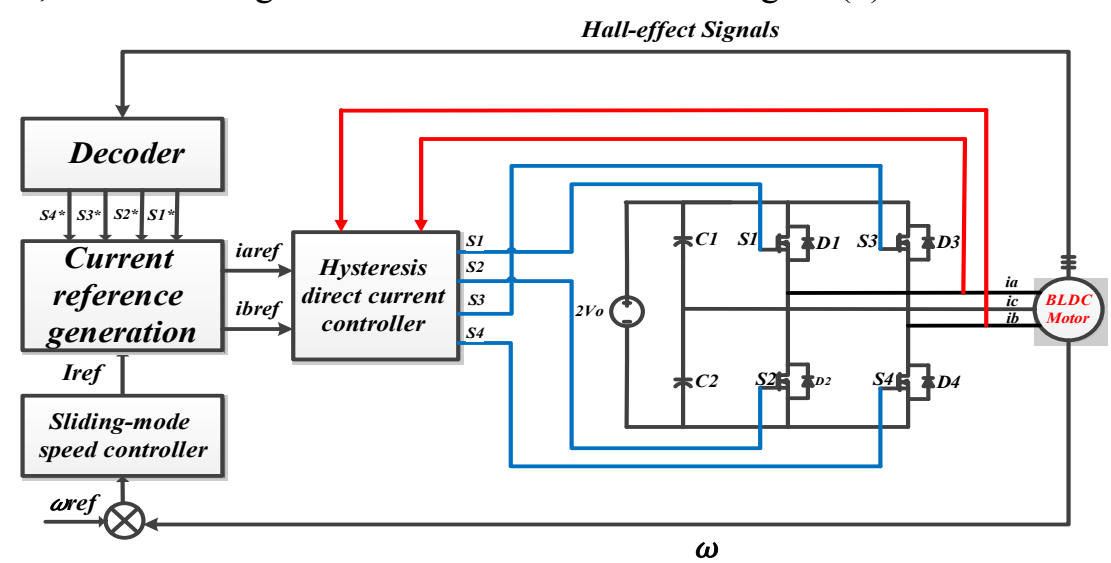

FIG. 8. THE BLOCK DIAGRAM OF THE PROPOSED SYSTEM

The detail of the sliding mode speed controller is shown in figure (9), and the detail of the current reference generation is shown in figure (10).

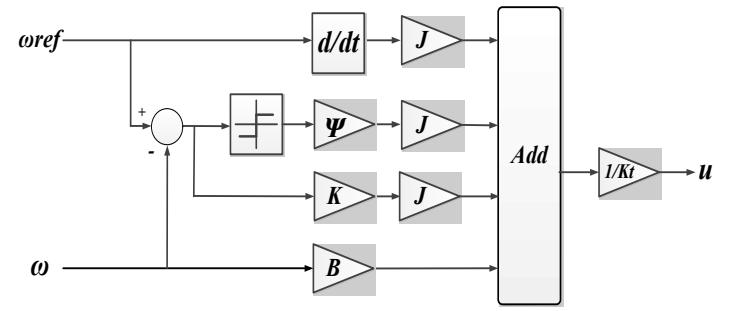

FIG. 9. THE BLOCK DIAGRAM OF THE SLIDING MODE SPEED CONTROLLER.

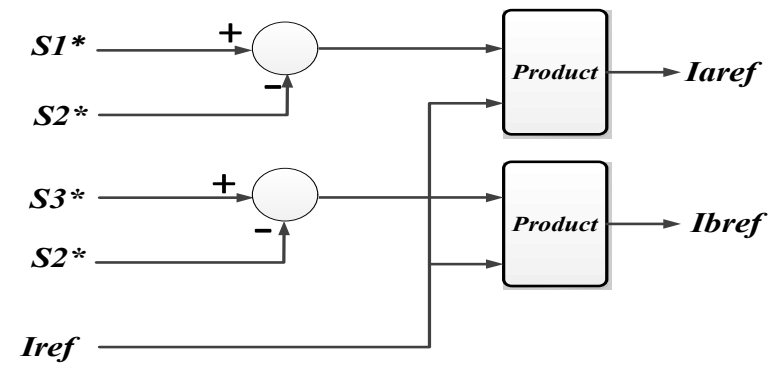

FIG. 10. THE BLOCK DIAGRAM OF THE CURRENT REFERENCE GENERATION.

The parameter and the constants of the BLDC motor are listed in the table (2). The parameters of the controller are listed in the table (3). 
TABLE 2.THE SPECIFICATION OF THE BLDC MOTOR $[12,13]$.

\begin{tabular}{ll}
\hline Parameter & Value \\
\hline Rated torque (N.m) & 3 \\
Rated speed (rpm) & 3000 \\
Stator resistance per phase (ohm) & 0.18 \\
Stator inductance per phase (H) & $0.835 \times 10^{3}$ \\
Magnets flux linkage (V.s) & 0.053603 \\
Voltage constant (peak V V-L/krpm) & 44.9059 \\
Torque constant (N.m/peak A) & 0.42882 \\
EMF flat area (Degree) & 120 \\
Inertia (kg.m ${ }^{2}$ ) & $0.62 \times 10^{-3}$ \\
Pole pair & 4 \\
\hline
\end{tabular}

TABLE 3.THEPARAMETERS OF THE CONTROLLER

\begin{tabular}{cl}
\hline Parameter & Value \\
\hline$\Psi$ & 1612.9 \\
$\mathrm{~K}$ & 32.258 \\
$\mathrm{~K}_{\mathrm{t}}$ & 0.42882 \\
$\mathrm{I}_{\text {Min }}$ & $0.95 \mathrm{I}_{\text {ref }}$ \\
$\mathrm{I}_{\text {Max }}$ & $1.05 \mathrm{I}_{\text {ref }}$ \\
\hline
\end{tabular}

Stator current waveforms are illustrated in figure (11). In figure (11), the motor is started at noload and then, at time instant 0.1 seconds, full-load torque $(3 \mathrm{~N} . \mathrm{m})$ is subjected. The torque profile at the same operating condition is shown in figure (12).

From figures (11) and (12), it is clear that the current waveforms are very close to ideal quasisquare form and the torque profile is smooth with low ripple. The speed response of the BLDC motor with different reference speed is shown in figure (13), where the reference speed is initially set at 200 $\mathrm{rpm}$ and then changed to $3000 \mathrm{rpm}$ (rated speed) at time instant 0.1 seconds. Figure (14) shows the speed response under different load conditions where the torque is suddenly increased from 1.5 to 3 N.m at time instant 0.1 seconds.
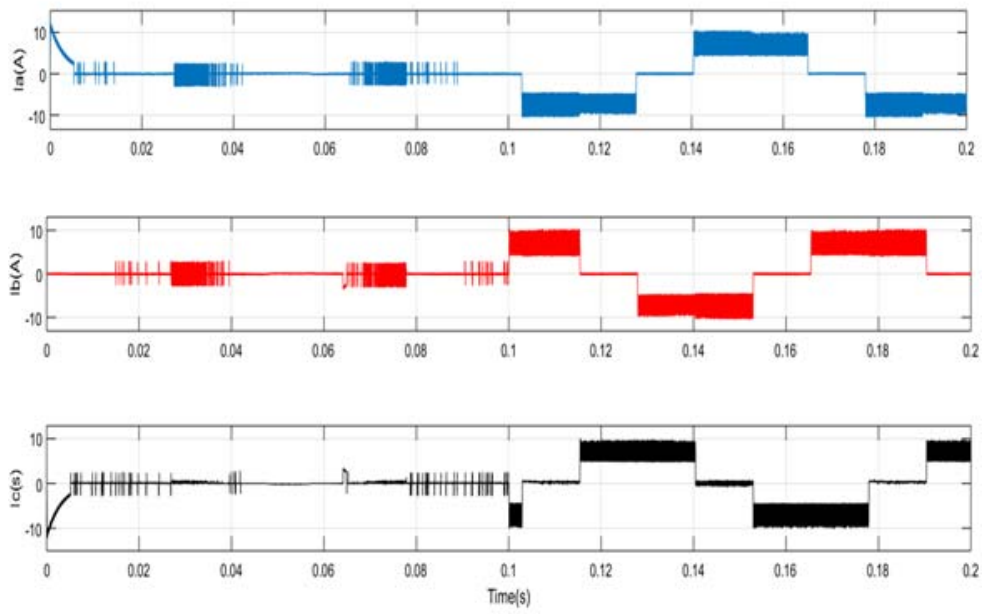

FIG. 11. CURRENT WAVEFORMS OF THE BLDC MOTOR. 


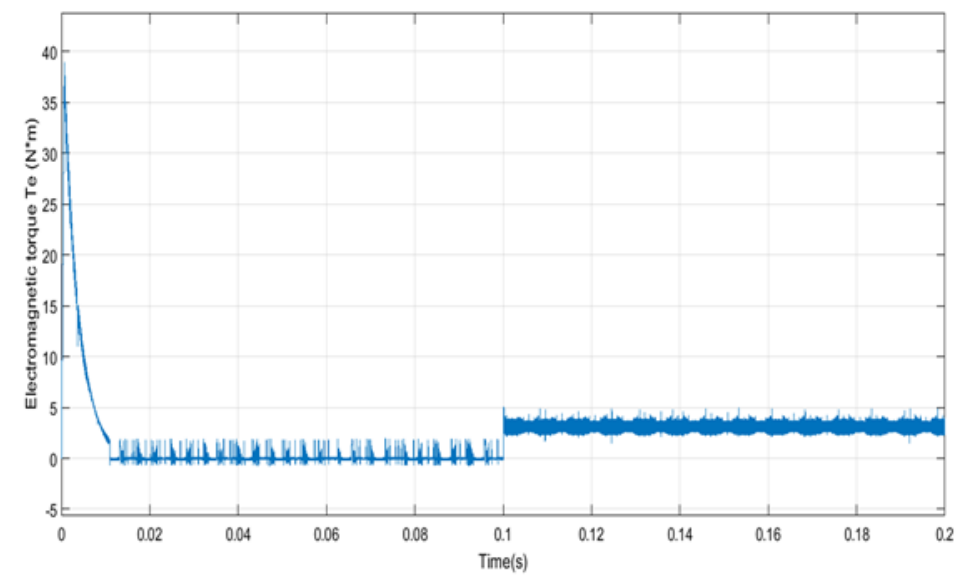

FIG. 12. TORQUE PROFILE OF THE BLDC MOTOR.

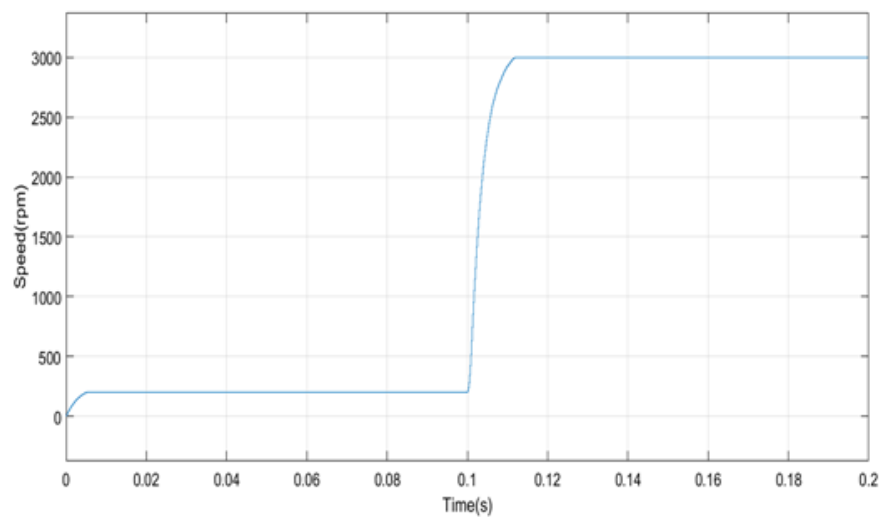

FIG. 13. THE SPEED RESPONSEWITH DIFFERENT REFERENCE SPEED.

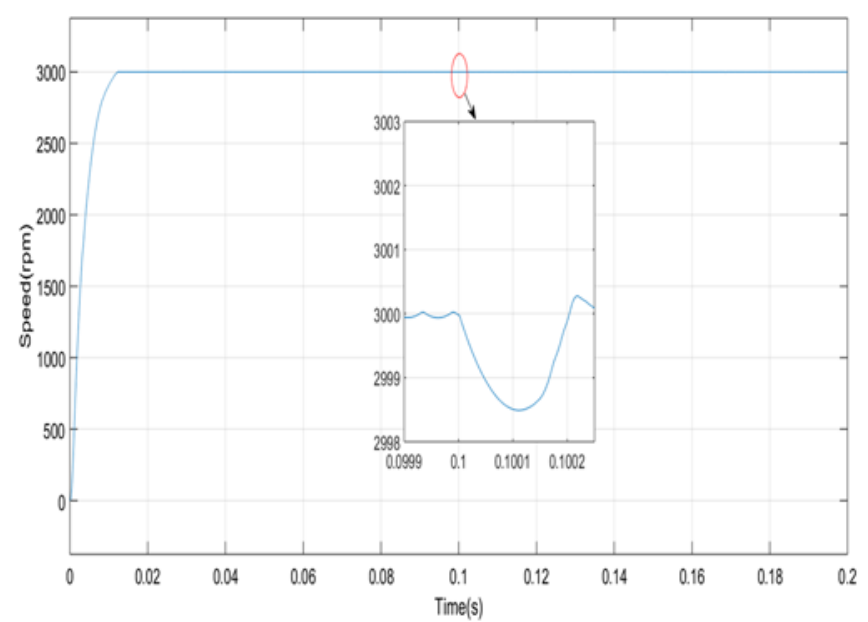

FIG. 14. THE SPEED RESPONSEWITH DIFFERENT LOAD TORQUE.

From figures (13) and (14), the simulation results of the speed verify the qualified performance of the controller where the rising time is extremely short, there is no overshoot, the steady-state error of the speed tends to be zero and the speed is unaltered even at the heavy change of load.

\section{CONCLUSION}

In this paper, the 4-switch BLDC motor drive system is introduced where cost saving is achieved. A new combination of sliding speed controller and hysteresis current controller is 
considered to meet the challenges caused by omitting pair of power switches. The superiority of the proposed strategy was demonstrated by Matlab/Simulink simulation, the simulation results show that the phase current is close to the quasi-square waveform and the ripple value is within the range of previously published works. Thus, the motor torque is smooth with reasonably accepted ripple. The requirements of the dynamic performance are attained, where the speed response has zero steady-state error and very short rising time with no overshoot at transient conditions. The propitious results certify the applicability of the proposed controller in low-cost 4-switch BLDC motor drive systems.

\section{REFERENCES}

[1] C. Xia, Permanent Magnet Brushless dc Motor Drives and Controls, Wiley Science Press, 2012.

[2] J. Fang,X. Zhou, and G. Liu," Precise Accelerated Torque Control for Small Inductance Brushless DC Motor", IEEE Transactions on Power Electronics, vol. 28, pp.1400-1412, March 2013.

[3] B. Lee , T. Kim, and M. Ehsani, " On the feasibility of four-switch three-phase BLDC motor drives for low-cost commercial applications: topology and control", IEEE Transactions on Power Electronics, vol. 18, pp.164-172, January 2003.

[4] A. H. Niasar, H. Moghbelli, and A. Vahedi ," Modeling, simulation and implementation of four-switch, Brushless DC motor drive based on switching functions", IEEE EUROCON 2009 conference, St.-Petersburg, Russia, May 2009.

[5] S. Ozturk, W. Alexander, and H. Toliyat, "Direct Torque Control of Four-Switch Brushless DC Motor With NonSinusoidal Back EMF”,IEEE Transactions on Power Electronics, vol. 25, pp.263-271, February 2010.

[6] Y. Shao, R. Yang, and Y. Fu, " Sliding mode speed control for brushless DC motor based on sliding mode torque observer", 2015 IEEE International Conference on Information and Automation, Lijiang, China, August 2015.

[7] C. Xia, Y. Xiao, and T. Shi, "Torque Ripple Reduction in Brushless DC Drives Based on Reference Current Optimization Using Integral Variable Structure Control”, IEEE Transactions on Industrial Electronics, vol. 61, pp.738752, February 2014.

[8] P. Lei,S. and et al., " Improved Four-Switch BLDCM Direct Current Control”, Research Journal of Applied Sciences, Engineering and Technology, vol. 6, pp.2483-2488, August 2013.

[9] F. Qiang, L. Hui, and Z. Hai-tao," Single-current-sensor Sliding Mode Driving Strategy For Four-switch Three-phase Brushless DC Motor“, 2006 IEEE International Conference on Industrial Technology, Mumbai, India, December 2006.

[10] V. Utkin, J. Guldner, and J. Shi, Sliding Mode Control in Electro-Mechanical Systems, CRC Press, 2009.

[11] P. Sowjanya, and S. Tarakalyani, "PI and Sliding Mode Control of Permanent Magnet Brushless DC Motor",International Journal of InnovativeTechnology and Research, vol. 1, pp. 497-502, September 2013.

[12] M. M. Ezzaldean, "Design of Speed-Controller for Brushless DC-Motor Based on Grey Predictor-PID Controller", Engineering and Technology Journal, vol. 36, pp. 900-905, August 2018.

[13] A. H Abed and M. M. Ezzaldean, "PSO-Based EKF Estimator Design for PMBLDC Motor",Engineering and Technology Journal, vol. 34, pp. 1651-1665, August 2016. 